\title{
Discussion on the Cost Efficiency of Library Information in Colleges and Universities
}

\author{
Wu Hong \\ Jianghan University, Hubei, Wuhan 430056
}

Keywords: college library; library information; cost efficiency

\begin{abstract}
With the rapid development of China's economy, the service function has been improved in college library, which improves its service level. The cost efficiency of library information also has become the priority of school development. Only by making full use of cost-benefit efficiency analysis of library information can be known and improved the problems in library development. Therefore, this paper discussed and analysed the cost efficiency of college library information.
\end{abstract}

\section{Introduction}

With the development of market economy, such teaching service department as college library is facing huge challenge. The vigorous development of market economy drives up prices, which leads to the tight funding of unprofitable institutions like college library. For the better service to students and teachers, cost efficiency must be analysed in college library information, with which book funds can be used reasonably.

\section{Basic procedures of cost-benefit analysis}

In the cost-benefit analysis of college library information, the basic procedure of cost efficiency should be clear so that analysis result can be in line with former prediction. Combining with knowledge on cost efficiency, we can know the procedures of cost-benefit analysis: first of all, we should know the projects of different sizes, expected benefits and costs, which needs the demonstration of products and demands and the accurate number of projects. Then the product value can be measured correctly and its current market value can be defined ${ }^{[1]}$. The project is practical if the benefit outweighs the cost and the specific numerical ratio, benefit-cost ratio, is greater than 1 .

\section{Cost-benefit analysis of library information}

\subsection{Accounting cost of library development}

\subsubsection{Generation cost of library information}

All the costs involved in library information activities is named generation cost. Development of internet information brings lots of convenience to social development. Special database is established using internet information to improve the library management while costs appear in the process of establishing database and purchasing books. The development of internet can promote the development of digital library, during which costs of information material would account for a large proportion in production cost of library information. With the advancement of times, college library would pay more attention to humanistic care for students and teachers and continuously improve the reading environment and service facilities inside to give a warm impression to students and teachers. The library would be rebuilt outside with architecture in line with current social fashion and renewal of facilities. In the construction comes the cost of building material, renewal of facilities and labour expenses. 


\subsubsection{Circulation cost of library information}

Circulation cost of library information comes from the circulation process of products. The time, money and communication fee consumed in buying products should be calculated reasonably. The library has so large collection that users need to search for books with the library's tips. Thus the perfection of service facilities in library would greatly affect users' time cost in selecting and purchasing.

\subsection{Opportunity cost of library information}

College libraries would carry out a series of library information activities in the long-term development and construction, which would produce opportunity cost. College would lose other profits if opportunity cost of library information holds large proportion in unchanged budget. Traditional algorithms can't accurately calculate such profit which should be calculated based on the average profit of social funds ${ }^{[2]}$. In order to making the best of the budget, relevant staff should fully understand the indicators of opportunity cost of library information activities. Only in this way can they handle the cost efficiency of library information.

\subsection{Problems of library information}

Operation funds of public department comes from taxation collected from private enterprise whose return rate is based on the discount rate of government sectors. It's generally believed that individual time preference is different from social time preference and that individual discount rate is greater than social one. Internet information is insufficient in the rapid-developing society and people have higher and higher demand on the quantity and quality of information. However, there are no enough high-quality information on the internet due to lack of organization and planning. The limited and unorganized information can be available but inefficient. In a society of information explosion, there would be increase on the operation cost as well as the time cost and communication cost of filtering information if the information can't be organized inefficiently, which is no benefit to the cost efficiency of library information and user experience. Therefore, to solve the cost efficiency problem in library information management, rapid-developing internet information should be made full use of and library information should be arranged orderly and reasonably.

\section{Measures to increase the cost efficiency of library information}

\subsection{Expand the source of books and improve the internet service facilities}

In the long-term development of college library, further analysis of library information is needed for the effective program to improve the cost efficiency of library information, make full use of book resource and improve the construction of service facilities. The network facilities in the library should be improved to make the source of library information more extensive to meet the different information needs of users, which can ensure the quantity and quality of library information ${ }^{[3]}$. The stable network facilities can meet the needs of users, improve the user traffic and greatly improve the library's book information efficiency. Using network information, library staff can complete the classification of books and periodicals more easily. In the vast sea of books, it is very important that books can be arranged orderly. The library also needs to establish thematic database, which can help users to search quickly and accurately, saving time cost for users. Users will be satisfied with such a fast and effective service, which will improve the efficiency of library book information. The increase of benefit can provide guarantee for improving library service facilities. In a word, it is a virtuous cycle of development.

\subsection{Establish a sound incentive mechanism}

College libraries belong to public department so the library staff don't get as huge reward or dividends as enterprise staffs. In this era of rapid economic development, the general economic treatment can no longer meet people's consumption demand, and the library staff will have an idle 
mentality with common salary, which is extremely unfavorable to the development of the library. Therefore, it is necessary to establish a sound incentive mechanism to enable library staff to have high enthusiasm during working hours and provide satisfactory services to users. Apart from rewards, it is also necessary to evaluate the work performance of library staff every month. Those who have high performance should be given extra bonus, motivating and urging them to do their work better. The perfect incentive mechanism can meet the consumption needs of library staff, improve the efficiency of library information, and provide guarantee for the development of college library.

\subsection{Establishing perfect knowledge service system}

It is necessary to establish a perfect knowledge service system in order to improve the benefit and construction of college library. Only when we realize the importance of knowledge service system can we establish a perfect one which can well summarize the work experience and knowledge of employees, improve their skills, increase their performance and improve the efficiency of library information ${ }^{[4]}$. The improvement of working skills can enable library staff to connect the needs of users with their knowledge and information, and provide perfect service for users. Users' satisfaction with library service will have a great influence on the benefit of library information. If they are satisfied with the library service, they will come to the library frequently in the future, which has a positive effect on the construction of the library.

\section{Conclusion}

With the development of society and technology, people's demand for knowledge will never be satisfied and they are always on the way of seeking knowledge so the construction and development of library is quite important. Cost-benefit analysis of library information would prevent unnecessary waste of funds in the construction of library so that there will be more budget in construction of service facilities. Rapid development of internet information technology would provide new opportunities for the development of many industries. Construction of college library should also catch up with the trends of times, using advantages of internet information to construct a modern library.

\section{References}

[1] Wang Xian. Cost-benefit analysis of library information[J]. Modern Economic Information, 2017(19):438.

[2] Zhang Na, Zhai Donghang. Cost-benefit analysis of college library information[J]. Intelligence, 2017(04):43.

[3] Wang Hui. Cost-benefit analysis of library information[J]. Henan Science \& Technology, 2014(04):213.

[4] Chen Rong, Zeng Hong. Cost effectiveness of college library information[J]. Journal of The Sichuan Society for Library Science, 2005(05):64-66. 